\title{
Ocorrências e aplicações de consórcio de microalgas: uma revisão sistemática da
}

\section{literatura}

\author{
Occurrences and applications of microalgae consortium: a systematic review of the literature
}

Ocurrencias y aplicaciones del consorcio de microalgas: una revisión sistemática de la literatura

Maria Helena Juvito da Costa

ORCID: https://orcid.org/0000-0003-3355-2373

Universidade Federal da Paraíba, Brasil

E-mail: helenajuvito@gmail.com

Nyelson da Silva Nonato

ORCID: https://orcid.org/0000-0003-2208-2265 Universidade Federal de Pelotas, Brasil

E-mail: nyelsonnonato@gmail.com

Sandra Naomi Morioka

ORCID: https://orcid.org/0000-0003-1741-4317 Universidade Federal da Paraíba, Brasil

E-mail: sandra.morioka@academico.ufpb.br

Mariana Moura Nóbrega

ORCID: https://orcid.org/0000-0003-0426-0988

Universidade Federal da Paraíba, Brasil

E-mail: mariana.nobrega@academico.ufpb.br

Sharline Florentino de Melo Santos

ORCID: https://orcid.org/0000-0002-5901-8892

Universidade Federal da Paraíba, Brasil E-mail: sharline@ct.ufpb.br

Darlan Azevedo Pereira

ORCID: https://orcid.org/0000-0002-6147-9014 Universidade Federal da Paraíba, Brasil

E-mail: azevedodarlan@gmail.com

\section{Resumo}

Esta revisão sistemática teve como objetivo investigar a literatura referente à ocorrência e aplicações de consórcio de microalgas, com finalidade de pesquisar artigos em periódicos internacionais indexados na base de dados Scopus. Foi utilizada a Systematic Literature Review (SLR) para mapear na literatura variáveis como publicações mais citadas, evolução das publicações, e periódicos mais relevantes. A pesquisa extraiu 278 artigos até junho de 2020. As publicações foram reduzidas a 224 artigos que compreendiam os dois tipos de consórcio propostos para investigação: 92 artigos do consórcio Microalga-Microalga (MM) e 132 artigos do consórcio Microalga-Bactéria (MB). Foram também investigados artigos que abrangessem consórcios no tratamento de efluentes, estes constituíram 116 publicações da amostra. Os resultados da pesquisa mostram que os estudos referentes a consórcio de microalgas adquiriram protagonismo nos últimos anos. Destacou-se a atuação de consórcios no tratamento de efluentes e o beneficiamento da biomassa microalgal na quantificação de bioativos de interesse como tema recorrente na literatura. Diante das possíveis aplicações, a literatura reporta a utilização da biomassa do consórcio de microalgas geradas durante o processo de tratamento de efluentes para sua potencialidade na produção de biocombustíveis. Por outro lado, a implementação de sistemas cultivo expansivos e outras alternativas para aplicação da biomassa ainda são pouco abordadas pela literatura sendo consideradas lacunas da pesquisa.

Palavras-chave: Consórcio; Microalgas-microalgas; Microalgas-bactérias; Produção de biomassa; Tratamento de efluentes; Bioativos.

\footnotetext{
Abstract

This systematic review aimed to investigate the literature regarding the occurrence and applications of microalgae consortia, in order to search for articles in international journals indexed in the Scopus database. The Systematic Literature Review (SLR) was used to map variables in the literature, such as the most cited publications, evolution of publications, and most relevant journals. The search extracted 278 articles by June 2020. The publications were reduced to 224 articles that comprised the two types of consortium proposed for investigation: 92 articles from the Microalga-Microalga (MM) consortium and 132 articles from the Microalga-Bacteria (MB) consortium. Articles covering consortia in the treatment of effluents were also investigated, which constituted 116 publications in the sample. The survey results show that studies referring to consortium of microalgae have gained prominence in recent
} 
years. The performance of consortia in the treatment of effluents and the processing of microalgal biomass in the quantification of bioactives of interest was highlighted as a recurrent theme in the literature. Given the possible applications, the literature reports the use of biomass from the consortium of microalgae generated during the effluent treatment process for its potential in the production of biofuels. On the other hand, implementation of expansive cultivation systems and other alternatives for the application of biomass are still poorly addressed in the literature and are considered research gaps.

Keywords: Consortium; Microalgae-microalgae; Microalgae-bacteria; Biomass production; Wastewater treatment; Bioactives.

\section{Resumen}

Esta revisión sistemática tuvo como objetivo investigar la literatura sobre la ocurrencia y aplicaciones de consorcios de microalgas, con el fin de buscar artículos en revistas internacionales indexadas en la base de datos Scopus. Para mapear variables en la literatura, se utilizó la Revisión de Literatura Sistemática (SLR), como las publicaciones más citadas, la evolución de las publicaciones y las revistas más relevantes. La búsqueda extrajo 278 artículos a junio de 2020. Las publicaciones se redujeron a 224 artículos que componían los dos tipos de consorcio propuestos para investigación: 92 artículos del consorcio Microalga-Microalga (MM) y 132 artículos del consorcio MicroalgaBacteria (MB). También se investigaron artículos sobre consorcios en el tratamiento de efluentes, que constituyeron 116 publicaciones de la muestra. Los resultados de la encuesta muestran que los estudios referentes al consorcio de microalgas han ganado protagonismo en los últimos años. La actuación de los consorcios en el tratamiento de efluentes y el procesamiento de biomasa de microalgas en la cuantificación de bioactivos de interés se destacó como un tema recurrente en la literatura. Dadas las posibles aplicaciones, la literatura reporta el uso de biomasa del consorcio de microalgas generadas durante el proceso de tratamiento de efluentes por su potencial en la producción de biocombustibles. Por otro lado, la implementación de sistemas de cultivo expansivos y otras alternativas para la aplicación de biomasa aún están poco abordadas en la literatura y se consideran vacíos de investigación.

Palabras clave: Consorcio; Microalgas-microalgas; Microalgas-bacterias; Producción de biomasa; Tratamiento de aguas residuales; Bioactivos.

\section{Introdução}

Cultivos de microalgas tanto em escala de bancada quanto em escala ampliada dependem de parâmetros cruciais para sua realização, seja o tipo de sistema de cultivo, a disponibilidade de nutrientes no meio, temperatura e irradiação, etc (Juneja et al., 2013; Moreno-Garcia et al., 2017; Pires et al., 2017). O cultivo de microalgas pode ser dividido em dois tipos de sistemas que relaciona a troca direta ou não dos gases com a atmosfera: aberto (lagoas circulares, tanques rasos sem agitação e raceways) e fechado (fotobiorreatores) (Chew et al., 2018; Fu et al., 2021). Cada sistema apresenta um conjunto de vantagens e desvantagens que devem ser balanceadas para o interesse final de aplicação da biomassa cultivada (Mata et al., 2010). Em geral, cultivos em escala comercial utilizam de sistemas abertos, entretanto para a obtenção de biocompostos de maior valor agregado, a cultura axênica é mais indicada e fotobiorreatores são utilizados. Para a implementação de sistemas fechados, os custos de instalação e operação são dominantes (Hu et al., 2018). Pesquisas recentes têm explorado sistemas de cultivo abertos (naturais ou artificiais) do tipo consórcio, co-cultivo, ou policultura, nos quais diferentes espécies de microalgas interagem entre si sinergicamente para que exista um controle na associação de metabólitos. Há também, consórcios de microalgas que incluem outros microrganismos, especialmente bactérias (Gonçalves et al., 2016).

O cultivo de microalgas em consórcios tem sido adotado para diversas aplicações, incluindo o tratamento de efluentes através da remoção de nutrientes presentes no meio, bem como na produção de biomassa e bioativos associados a esta (Gonçalves et al., 2016; Liu et al., 2017; Zhang et al., 2020; Fallahi et al., 2021). Estudos preliminares já relataram, que esse sistema fornece uma proteção em relação à invasão de outros microrganismos e apresenta uma elevada produtividade de biomassa com composição diversificada de metabólitos similar a cada uma das espécies que fazem parte dele (Rashid et al., 2019; Nath et al., 2019). Das inúmeras aplicações para as microalgas, pode-se destacar seu caráter biorremediador no processo de remoção de nitrogênio, fósforo, carbono e metais presentes em efluentes de origem agrícola, industrial, municipal, etc. A utilização de consórcios de microalgas-microalgas e microalgas-bactérias para fins de remoção desses nutrientes apresentam vantagens, uma vez que combina microrganismos com diferentes atividades metabólicas para a construção de um sistema 
biológico robusto com a produção de diferentes metabolitos (Magdouli et al., 2016; Perera et al., 2019; González-Gálvez et al., 2020).

Trabalhos de revisão da literatura sobre consórcios de microalgas-microalgas (MM) e microalgas-bactérias (MB) exploram aspectos relacionados a três principais abordagens: (1) Desafios e avanços do consórcio, desde os modos de cultivo para incrementação metabólica ao melhoramento metodológico das ferramentas de acompanhamento das culturas com diferentes microrganismos (Magdouli et al., 2016; Rossi et al., 2020); (2) Biorremediação de efluentes e solo, investigando as interações cooperativas entre microrganismos na geração de melhorias produtivas, maiores rendimentos financeiros, menores gastos na produção e máxima remoção de nutrientes (Gonçalves et al., 2016; Mujtaba et al., 2016; Manzoor et al., 2016; Liu et al., 2017; Perera et al., 2018; Perera et al., 2019; Fu \& Secundo, 2016) e (3) Aplicações biotecnológicas, como produção de gases, condições de cultivo extremas, redução dos gargalos produtivos e biomanofaturamento (Ishika et al., 2017; Padmaperuma et al., 2018; Fakhimi et al., 2020; Zhang et al., 2020).

Todas essas revisões da literatura trazem contribuições relevantes sobre aspectos específicos dos consórcios de MM ou MB. Este artigo tem como objetivo oferecer uma visão geral da literatura sobre os consórcios de MM e MB, para fornecer uma base de conhecimento das abordagens existentes e orientar futuras pesquisas no campo. Portanto, uma revisão sistemática da literatura (RSL) foi conduzida para responder às seguintes questões de pesquisa relacionadas à literatura dos consórcios MM e MB: RQ1. Quais são as principais características dessa literatura?; RQ2. O que é abordado e quais são as principais conclusões dos artigos mais influentes?; RQ3. Quais são as principais aplicações relatadas?; RQ4. Quais são as tendências e lacunas de pesquisa?

\section{Métodos}

A revisão sistemática da literatura (RSL) é uma metodologia confiável, rigorosa e auditável que apresenta uma avaliação justa da pesquisa disponível relevante para uma determinada questão de pesquisa, área de tópico ou fenômeno de interesse (Kitchenham, 2004). Além disso, permite conclusões razoavelmente claras sobre o que é e o que não é conhecido em um campo de conhecimento pela identificação de estudos existentes, seleção e avaliação de contribuições, análise e síntese de dados e relato de evidências (Denyer; Tranfield, 2009). Esta pesquisa utilizou procedimentos organizados, transparentes e replicáveis e foi realizada em quatro etapas: planejamento da pesquisa; definição da amostra; análise de amostra; e fechamento e disseminação (Figura 1).

Figura 1 - Etapas da pesquisa.

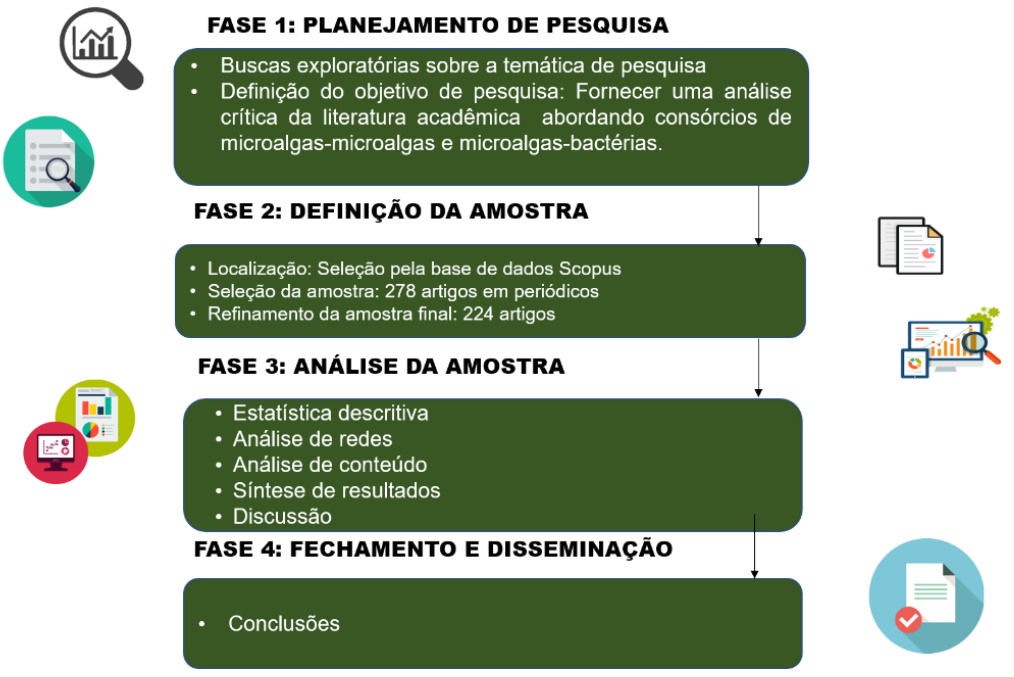

Fonte: Autores (2021). 
A etapa 1 consistiu em uma busca exploratória para melhor compreensão do tema. Foi conduzido na lógica de tentativa e erro (teste de combinações de palavras-chave para filtros em bases de dados de artigos) e acesso a referências de referências. Esses procedimentos permitiram estabelecer os objetivos e questionamentos da pesquisa e determinar os parâmetros utilizados na próxima etapa, a definição da amostra.

A segunda etapa incluiu: (i) localização; (ii) seleção da amostra; e (iii) refinamento da amostra. A amostra de artigos foi obtida por meio de consulta à base de dados Scopus, devido ao mérito científico de suas publicações. A amostra foi selecionada em 10 de junho de 2020 com base nos seguintes parâmetros: (1) título ou resumo ou palavra-chave: "consorti * OR cocult * OR co-cult * OR mix"; (2) título: "Microalga *”; (3) Ano: "todos os anos"; (4) idioma: inglês; (5) Tipo de documento: artigo e revisões. Foram encontradas 278 publicações. Em seguida, os títulos e resumos foram analisados com o objetivo de excluir as publicações sem aderência aos objetivos da pesquisa, ou seja, artigos que não abordam os consórcios de MM e MB. A amostra final é composta por 224 artigos, 92 no MM e 132 no MB.

A etapa de análise da amostra iniciou com a organização e codificação dos artigos em planilhas do Excel® incluindo informações relacionadas às questões de pesquisa: (a) publicação (periódico, ano, palavras-chave); (b) tipo de consórcio (MM ou MB); e (c) tipo de aplicação (bioativos, tratamento de águas residuais ou ambos). Dependendo da aplicação, os trabalhos também foram examinados por: (d) bioativos (proteínas, lipídios, ácidos graxos e/ou carboidratos); e (e) origem das águas residuais (industriais, agroindustriais, municipais ou outras). A maior parte das informações foi obtida por meio de títulos, resumos e palavras-chave, mas em alguns casos, também foi consultado o texto completo. Em seguida, foram realizadas estatísticas descritivas incluindo distribuição anual, periódicos mais frequentes, artigos mais citados e distribuição dos artigos de acordo com o tipo de consórcio (MM ou MB). Uma análise de rede nas palavras-chave dos autores também foi realizada usando o software Vos-Viewer.

Quadro 1 - Resumo descritivo das etapas de análise da amostra.

\begin{tabular}{|c|c|c|}
\hline $\begin{array}{l}\text { Questões de pesquisa relacionadas à } \\
\text { literatura dos consórcios MM e MB }\end{array}$ & Procedimentos de análise da amostra & Resultados \\
\hline $\begin{array}{l}\text { RQ1. Quais são as principais características } \\
\text { dessa literatura? }\end{array}$ & $\begin{array}{c}\text { Estatísticas descritivas (distribuição anual, } \\
\text { periódicos mais frequentes, artigos mais citados e } \\
\text { distribuição dos artigos de acordo com o tipo de } \\
\text { consórcio). } \\
\text { Análise de redes. }\end{array}$ & Seção 3.1 \\
\hline $\begin{array}{l}\text { RQ 2. O que é abordado e quais são as } \\
\text { principais conclusões dos artigos mais } \\
\text { influentes? }\end{array}$ & $\begin{array}{l}\text { Análise de conteúdo (breve descrição dos dez } \\
\text { artigos mais citados). }\end{array}$ & Seção 3.2 \\
\hline $\begin{array}{l}\text { RQ3. Quais são as principais aplicações } \\
\text { relatadas }\end{array}$ & Estatística descritiva, Análise de conteúdo. & Seção 4 \\
\hline $\begin{array}{l}\text { RQ4: Quais são as tendências e lacunas de } \\
\text { pesquisa? }\end{array}$ & Análise de conteúdo. & Seção 5 \\
\hline
\end{tabular}

Fonte: Autores (2021).

\section{Visão Geral da Literatura}

Esta seção apresenta uma visão geral da literatura MM e MB, descrevendo e analisando as principais características da literatura (RQ1) e os artigos mais influentes (RQ2).

\subsection{Principais características da literatura}

Para compreensão do que a literatura fornece sobre os consórcios de microalgas-microalgas e microalgas-bactérias, foi feita uma análise da evolução anual, a distribuição do número de publicações abordando cada tipo de consórcio e os principais periódicos. 
A primeira publicação sobre consórcio MB data de 1996 (Paerl \& Pinckney,1996). O trabalho buscou avaliar estrutural e funcionalmente consórcios no contexto da produção aquática, energia e dinâmica do ciclo de nutrientes. Lima et al., (2004) em seu trabalho buscou avaliar a biodegradação de p-clorofenol e p-nitrofenol por um consórcio de microalgas: Chlorella vulgaris e Coenochloris pyrenoidosa em dois foto-regimes diferentes.

Entre 1996 e 2009 apenas 7 artigos foram publicados, uma média de 0,54 artigo/ano. A partir de 2010, os artigos passaram a ser publicados todos os anos, com uma média de 19,72 publicações/ano (Figura 2). A partir de 2016 houve um aumento significativo de publicações relacionadas ao tema. Vale salientar que os dados referentes ao ano de 2020 contemplam apenas publicações até o mês de junho e apesar disso, a análise de regressão foi usada para analisar as tendências de crescimento linear, obtendo uma tendência positiva $(\mathrm{R}=0,71)$. A análise individual para as tendências de crescimento linear para os dois tipos de consórcios da pesquisa mostrou que o crescimento se deu de forma positiva, sendo $\mathrm{R}=0,75$ para $\mathrm{o}$ consórcio de Microalgas-Microalgas (MM), e R= 0,64 para o consórcio de Microalgas-Bactérias (MB).

Figura 2 - Evolução do número de artigos ao longo dos anos.

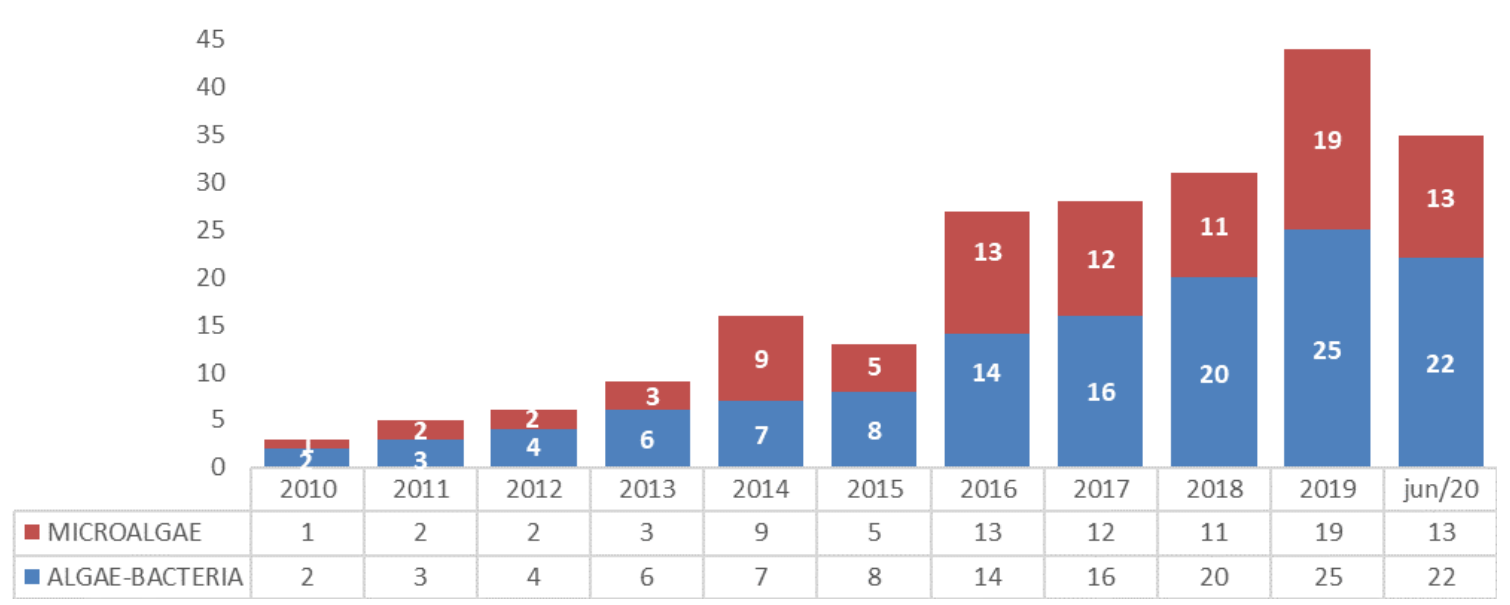

Fonte: Autores (2021).

A Figura 3 mostra uma rede de palavras-chave do autor. A rede tem um total de 20 termos com ocorrência mínima de 5 vezes. Os termos são agrupados em quatro clusters identificados pela cor dos nós. O tamanho dos nós indica a frequência de ocorrência do termo, enquanto a espessura das linhas representa a intensidade de coocorrência, ou seja, a frequência com que dois termos aparecem juntos em um mesmo papel. Observa-se que as palavras mais marcantes são "microalgae", "wastewater" e "consortium". 
Figura 3 - Rede de palavras-chave.

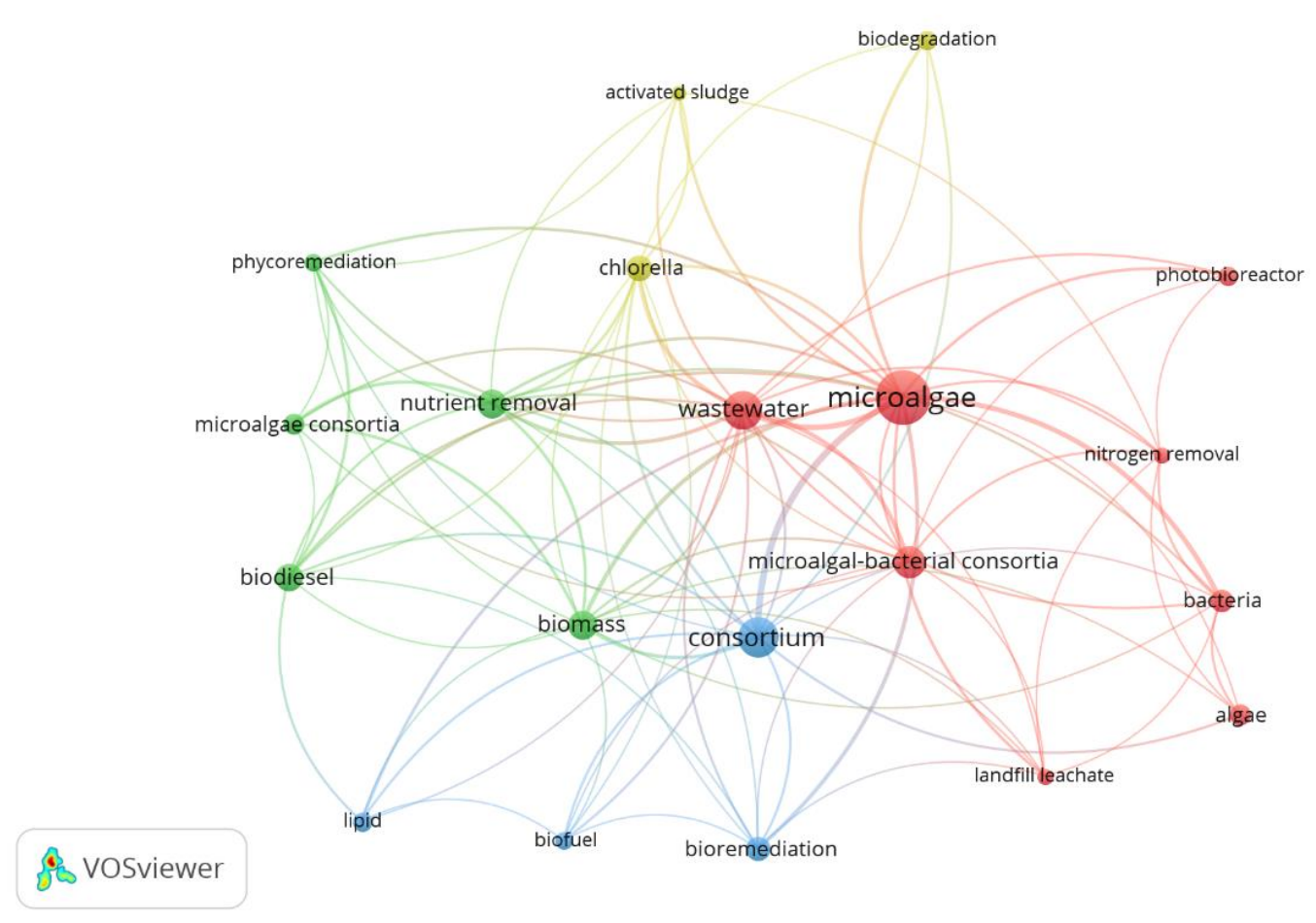

Fonte: Autores (2021).

- Cluster $1:$ Vermelho $\rightarrow$ Demonstra a forte conexão das microalgas como organismo de interesse e sua potencialidade no tratamento de águas residuais que servem como fonte nutricional para o desenvolvimento das espécies presentes. Destaca-se a utilização de consórcios de microalgas-bactérias que podem atuar sinergicamente na remoção de componentes presentes em águas residuais caracterizadas pela elevada demanda de nitrogênio, fósforo e outros contaminantes.

- Cluster 2: Verde $\rightarrow$ A conexão entre a biomassa, remoção de nutrientes, ficorremediação e biodiesel a partir do consórcio de microalgas é extremamente visível, demonstrando a forte relação de valor. Efluentes ricos em nutrientes são abundantes podendo ser implementados como meios de cultivo alternativo para consórcio de microalgas e obtenção da biomassa que pode ser destinada para a produção de biodiesel.

- Cluster 3: Azul $\rightarrow$ Esse grupo tem como assunto central a projeção das aplicações dos consórcios, na biorremediação de efluentes e produção de biocombustíveis.

- Cluster 4: Mostarda $\rightarrow$ Destaca o gênero Chlorella como potencial microrganismo a ser inserido no consórcio microalgamicroalga ou microalga-bactéria para atuar como agente biorremediador.

Como todos os artigos da amostra citam "microalgae" e "consortium" ou suas variações (por exemplo, consortia, coculture, co-cultivation e mix) como palavras-chave, esses termos foram excluídos da rede para facilitar a visualização (Figura 4). 
Figura 4 - Rede de palavras-chave excluindo termos "microalgae" e "consortium".

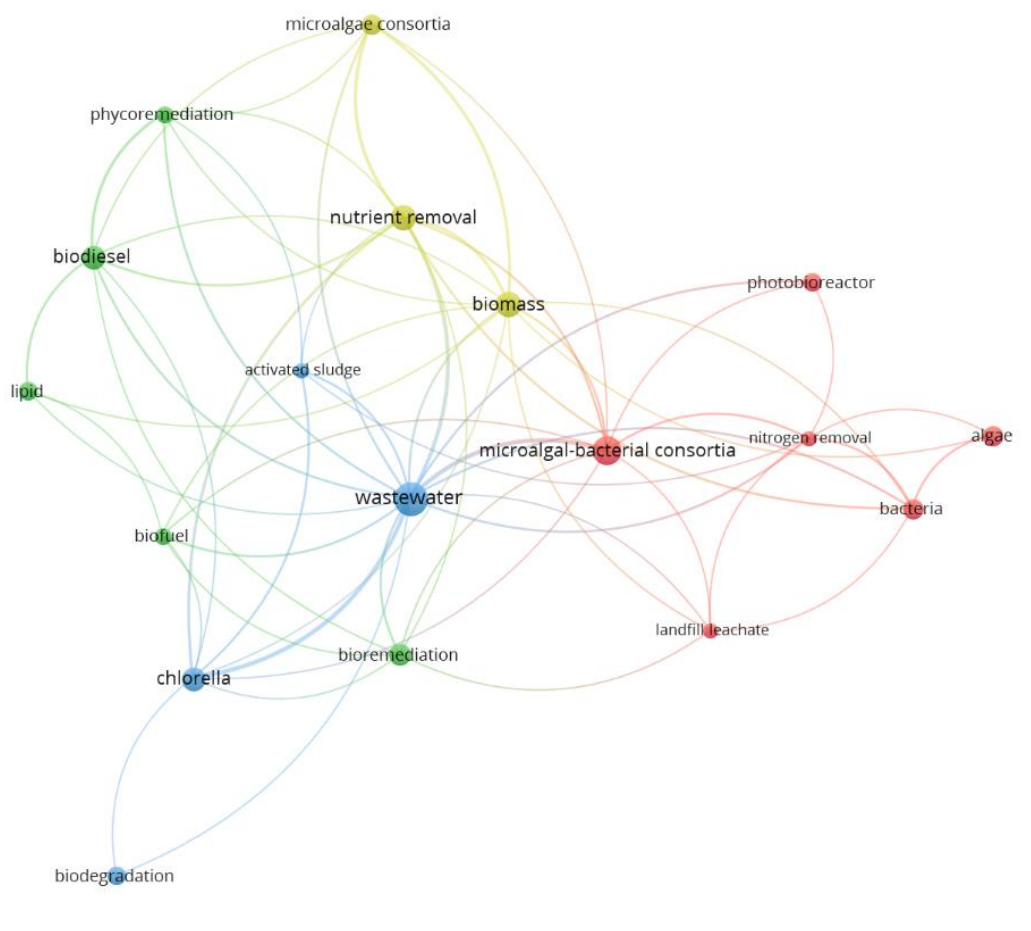

Fonte: Autores (2021).

- Cluster 1: Azul $\rightarrow$ Demonstra o gênero Chlorella como organismo de biorremediação. A literatura reporta utilização desse gênero de microalgas no tratamento de efluentes e acúmulo de lipídios (Chiu et al., 2015; Dayana Priyadharshini et al., 2021; Wu et al., 2020).

- Cluster 2: Vermelho $\rightarrow$ Destaca a atuação do consórcio de microalgas-bactérias na remoção de nitrogênio em águas residuais.

- Cluster 3: Mostarda $\rightarrow$ Evidencia a atuação dos consórcios de microalgas na remoção de nutrientes com o beneficiamento da biomassa gerada ao fim do cultivo.

- Cluster 4: Verde $\rightarrow$ Revela a principal aplicação da biomassa (biodiesel) gerada durante o processo de remediação coincidindo com o principal bioativo abordado pelos trabalhos disponíveis na literatura (Seção 4.2).

Mesmo retirando os termos de busca, a amostra condiz com os assuntos que se pretendeu avaliar, garantindo a confiabilidade da mesma.

Com a finalidade de entender melhor a distribuição dos trabalhos publicados, foi montada a distribuição dos principais periódicos (10) que abrangem os dois tipos de consórcio abordados na pesquisa e suas métricas (Quadro 2). De um total de 224 artigos, estes são os que mais contribuem com o assunto, representando 80,6\% dos artigos da amostra. Dentre os periódicos que mais publicam sobre o tema estão também os mais citados, destacam-se: Bioresource Technology com 31 artigos (13,84\%) e Algal Research com 10 artigos (4,46\%), que partilham deste protagonismo no que tange ao consórcio de microalgas. Chemical Engineering Journal foi o periódico com maior JCR, 13.273, seguido da revista Water Research e Bioresource Technology. A maioria dos periódicos está relacionado à pesquisa em biotecnologia, microbiologia e poluição, possuindo JCR que varia de 3.215 a 13.273, para uma média de 7.05. 
Research, Society and Development, v. 11, n. 1, e11511124421, 2022

(CC BY 4.0) | ISSN 2525-3409 | DOI: http://dx.doi.org/10.33448/rsd-v11i1.24421

Quadro 2 - Métricas dos principais periódicos que publicaram sobre consórcios microbianos.

\begin{tabular}{|c|c|c|c|}
\hline Periódico & JCR (2021)* & CiteScore (2020)** & $\begin{array}{c}\text { Percentual de } \\
\text { Publicação (\%) }\end{array}$ \\
\hline Bioresource Technology & 9.642 & 14.8 & 13,84 \\
\hline Journal of Applied Phycology & 3.215 & 5.0 & 4,91 \\
\hline Algal Research & 4.401 & 6.9 & 4,46 \\
\hline Water Science and Technology & 1.915 & 3.3 & 2,68 \\
\hline Water Research & 11.236 & 15.6 & 2,68 \\
\hline $\begin{array}{c}\text { Journal of Environmental } \\
\text { Management }\end{array}$ & 6.789 & 9.8 & 2,23 \\
\hline $\begin{array}{c}\text { Environmental Science and Pollution } \\
\text { Research }\end{array}$ & 4.223 & 17.2 & 2,23 \\
\hline $\begin{array}{c}\text { Chemical Engineering Journal } \\
\text { Applied Microbiology and } \\
\text { Biotechnology }\end{array}$ & 13.273 & 7.0 & 2,23 \\
\hline $\begin{array}{c}\text { International Biodeterioration and } \\
\text { Biodegradation }\end{array}$ & 4.813 & 9.2 & 1,79 \\
\hline
\end{tabular}

*JCR, 2021 (https://impactfactorforjournal.com/jcr-2021/); **CiteScore, 2020 (https://www.scopus.com/sources.uri) Fonte: Autores (2021).

Assim como o JCR, o CiteScore definido pela base Scopus contribui na avaliação do desempenho dos periódicos, com uma métrica baseada na relação do número de documentos publicados pelo número de citações realizadas num período correspondente, quatro anos. Assim como no JCR observamos as mesmas revistas com as pontuações mais altas no CiteScore (Quadro 2), são elas: Chemical Engineering Journal foi o periódico com maior nota (17.2), seguido da revista Water Research (15.6) e Bioresource Technology (14.8).

\subsection{Artigos mais influentes}

Um indicador importante para avaliar o impacto da pesquisa é o número de citações (Bornmann; Leydesdorff, 2013; Sorz et al, 2020). Para responder à RQ2: O que é abordado e quais são as principais conclusões dos artigos mais influentes?, foram identificados os 10 artigos mais citados (Quadro 3).

Quadro 3 - Artigos mais citados.

\begin{tabular}{|c|c|c|c|c|}
\hline Título & Autores (ano) & $\begin{array}{l}\text { Número de } \\
\text { citações; } \\
\text { (média por } \\
\text { ano) }\end{array}$ & $\begin{array}{l}\text { Tipo de } \\
\text { consórcio; } \\
\text { (Review ou } \\
\text { não) } \\
\end{array}$ & Periódico \\
\hline $\begin{array}{c}\text { A mini-review of microbial consortia: } \\
\text { Their roles in aquatic production and } \\
\text { biogeochemical cycling }\end{array}$ & $\begin{array}{l}\text { Paerl H.W., Pinckney J.L. } \\
\text { (1996) }\end{array}$ & $324(14)$ & $\begin{array}{c}\mathrm{MB}^{*} \\
\text { (Literature } \\
\text { Review) }\end{array}$ & $\begin{array}{l}\text { Microbial } \\
\text { Ecology }\end{array}$ \\
\hline $\begin{array}{l}\text { Consortia of cyanobacteria/microalgae } \\
\text { and bacteria: Biotechnological potential }\end{array}$ & $\begin{array}{l}\text { Subashchandrabose S.R., } \\
\text { Ramakrishnan B., Megharaj } \\
\text { M., Venkateswarlu K., } \\
\text { Naidu R. (2011) }\end{array}$ & $191(21)$ & $\begin{array}{c}\text { MB } \\
\text { (Literature } \\
\text { Review) }\end{array}$ & $\begin{array}{l}\text { Biotechnolog } \\
\text { y Advances }\end{array}$ \\
\hline $\begin{array}{c}\text { Increased growth of the microalga } \\
\text { Chlorella vulgaris when coimmobilized } \\
\text { and cocultured in alginate beads with the } \\
\text { plant-growth-promoting bacterium } \\
\text { Azospirillum brasilense }\end{array}$ & $\begin{array}{c}\text { Gonzalez L.E., Bashan Y. } \\
\text { (2000) }\end{array}$ & $179(9)$ & $\mathrm{MB}$ & $\begin{array}{c}\text { Applied and } \\
\text { Environmenta } \\
1 \\
\text { Microbiology }\end{array}$ \\
\hline $\begin{array}{l}\text { Growth and nitrogen removal capacity of } \\
\text { Desmodesmus communis and of a natural } \\
\text { microalgae consortium in a batch culture } \\
\text { system in view of urban wastewater } \\
\text { treatment: Part I }\end{array}$ & $\begin{array}{c}\text { Samori G., Samori C., } \\
\text { Guerrini F., Pistocchi R. } \\
\text { (2013) }\end{array}$ & $129(18)$ & $\mathrm{MM}^{*}$ & $\begin{array}{c}\text { Water } \\
\text { Research }\end{array}$ \\
\hline $\begin{array}{l}\text { A review on the use of microalgal } \\
\text { consortia for wastewater treatment }\end{array}$ & $\begin{array}{l}\text { Goncalves A.L., Pires } \\
\text { J.C.M., Simoes M. (2017) }\end{array}$ & $123(41)$ & $\begin{array}{l}\mathrm{MM} \\
\text { (Literature } \\
\text { Review) }\end{array}$ & $\begin{array}{c}\text { Algal } \\
\text { Research }\end{array}$ \\
\hline
\end{tabular}


Research, Society and Development, v. 11, n. 1, e11511124421, 2022

(CC BY 4.0) | ISSN 2525-3409 | DOI: http://dx.doi.org/10.33448/rsd-v11i1.24421

\begin{tabular}{|c|c|c|c|c|}
\hline $\begin{array}{l}\text { Biomass and bioenergy production } \\
\text { potential of microalgae consortium in } \\
\text { open and closed bioreactors using } \\
\text { untreated carpet industry effluent as } \\
\text { growth medium }\end{array}$ & $\begin{array}{c}\text { Chinnasamy S., Bhatnagar } \\
\text { A., Claxton R., Das K.C. } \\
\text { (2010) }\end{array}$ & $107(11)$ & MM & $\begin{array}{l}\text { Bioresource } \\
\text { Technology }\end{array}$ \\
\hline $\begin{array}{l}\text { Sequential removal of heavy metals ions } \\
\text { and organic pollutants using an algal- } \\
\text { bacterial consortium }\end{array}$ & $\begin{array}{c}\text { Munoz R., Alvarez M.T., } \\
\text { Munoz A., Terrazas E., } \\
\text { Guieysse B., Mattiasson B. } \\
\text { (2006) }\end{array}$ & $107(8)$ & $\mathrm{MB}$ & Chemosphere \\
\hline $\begin{array}{c}\text { Nitrogen transformations under different } \\
\text { conditions in open ponds by means of } \\
\text { microalgae-bacteria consortium treating } \\
\text { pig slurry }\end{array}$ & $\begin{array}{c}\text { Gonzalez-Fernandez C., } \\
\text { Molinuevo-Salces B., } \\
\text { Garcia-Gonzalez M.C. } \\
\text { (2011) }\end{array}$ & $81(9)$ & MB & $\begin{array}{l}\text { Bioresource } \\
\text { Technology }\end{array}$ \\
\hline $\begin{array}{l}\text { Cultivation of algae consortium in a dairy } \\
\text { farm wastewater for biodiesel production }\end{array}$ & $\begin{array}{l}\text { Hena S., Fatimah S., } \\
\text { Tabassum S. (2015) }\end{array}$ & $78(16)$ & MM & $\begin{array}{c}\text { Water } \\
\text { Resources and } \\
\text { Industry }\end{array}$ \\
\hline $\begin{array}{l}\text { Evaluation of microalgal consortia for } \\
\text { treatment of primary treated sewage } \\
\text { effluent and biomass production }\end{array}$ & $\begin{array}{c}\text { Renuka N., Sood A., Ratha } \\
\text { S.K., Prasanna R., } \\
\text { Ahluwalia A.S. } \\
\text { (2013) }\end{array}$ & $75(11)$ & MM & $\begin{array}{l}\text { Journal of } \\
\text { Applied } \\
\text { Phycology }\end{array}$ \\
\hline
\end{tabular}

*Legenda: MM (Consórcio de microalgas- microalgas); MB (Consórcio de microalgas-bactérias). Fonte: Autores (2021).

Os dez artigos mais influentes estão igualmente distribuídos quanto ao tipo de consórcio, 5 tratam de MB e 5 de MM. Os três artigos com maior número de citações abordam consórcios do tipo MB. O primeiro deles consiste numa revisão da literatura. No entanto, a média anual de citações também é um parâmetro a ser considerado (Sorz et al., 2020). Segundo essa métrica, o artigo mais relevante dentre os dez também é uma revisão da literatura, mas sobre consórcios do tipo MM.

A Figura 5 apresenta a distribuição das citações dos 10 artigos mais influentes da amostra ao longo dos anos. A partir do ano de 2005 observa-se o surgimento de novas pesquisas referentes ao tema, diversificando os autores que trabalhavam com o consórcio de microrganismos fotossintéticos ou não. 
Figura 5 - Distribuição das citações dos artigos mais influentes ao longo do anos.

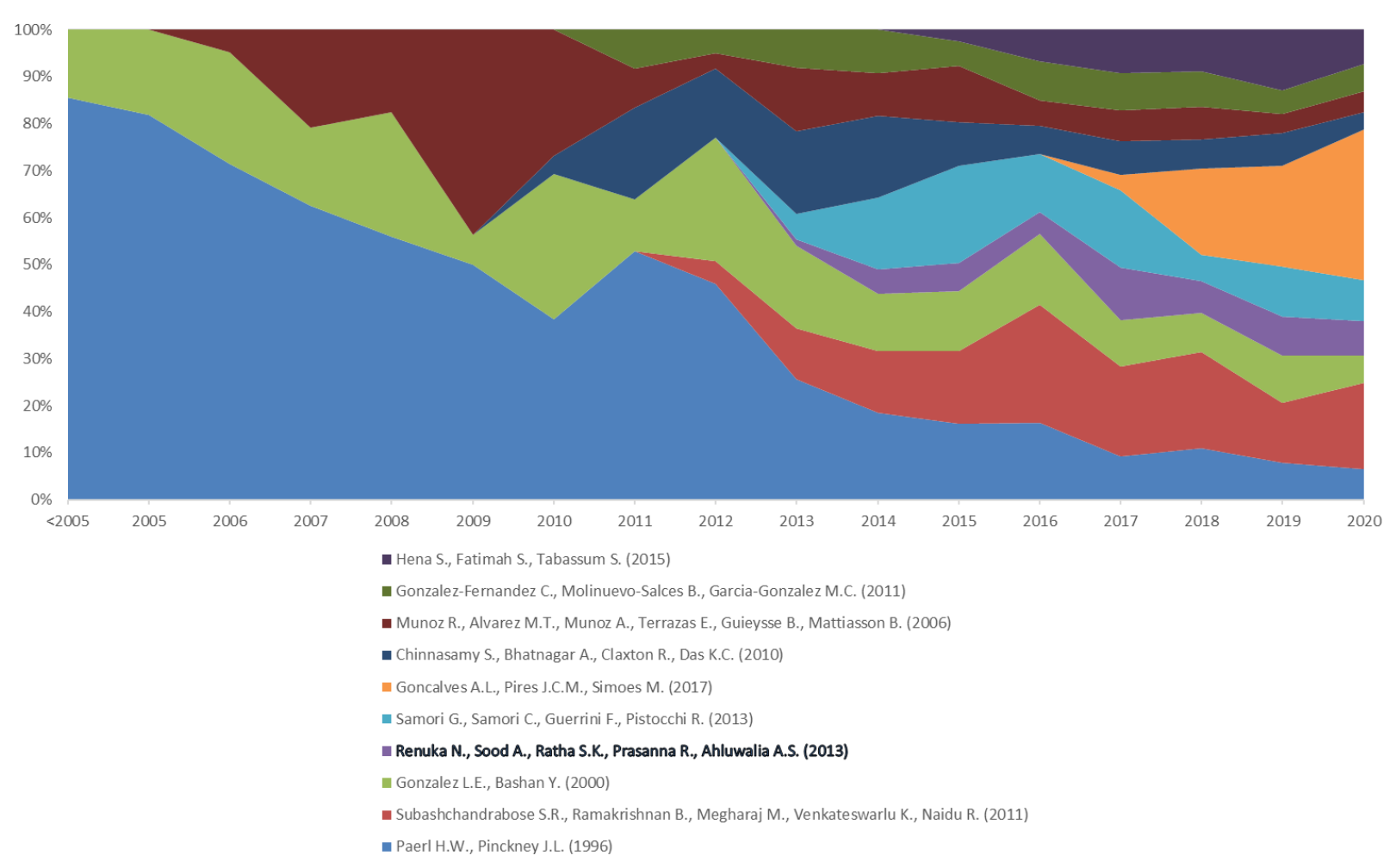

Fonte: Autores (2021).

O artigo mais citado da amostra foi publicado por Paerl H.W. em colaboração com Pinckney J.L. da University of North Carolina nos EUA e obteve ao todo 324 citações, tendo uma frequência média anual de 14 citações durante o período de análise. Paerl e Pinckney (1996) realizaram um levantamento bibliográfico acerca da interação de procariotos e eucariotos microbianos em ambientes naturais e sua importância ecológica. Entre os resultados observados, podemos destacar que para avaliar os impactos em macroescala das interações consorciadas, os estudos devem se concentrar na gama de escalas temporais (minutos a horas) e espaciais (mícrons a centímetros) relevantes que controlam a produção microbiana, a troca de nutrientes e o ciclo. O trabalho foi amplamente citado ao longo dos anos e, mesmo sendo a publicação mais antiga sobre consórcio de microalgas, continua influenciando as pesquisas atuais, se tornando uma referência registrada no assunto. Das duas vezes que foi citado no periódico da Nature (JCR: 42.779; CiteScore:51), foi utilizado para fundamentar a introdução dos trabalhos, discutindo a importância ecológica dos microrganismos na ciclagem dos nutrientes, e, consequentemente, sua influência no ambiente, desde a degradação da matéria orgânica em diferentes nichos microbianos ao fluxo de carbono não fixado (Chapin et al., 2000; Smith et al., 2019).

Seguindo a listagem de publicações com maior número de citações, temos em segundo lugar o artigo de revisão desenvolvido por Subashchandrabose et al., (2011), publicado no periódico Biotechnology Advances e escrito por pesquisadores da Austrália (University of South Australia) e Índia (Universidade Sri Krishnadevaraya). Trata-se de uma revisão que destaca o potencial de consórcios de microalgas-cianobactérias e bactérias como um sistema autossustentável para a desintoxicação de poluentes ambientais e remoção de nutrientes associada à produção de metabólitos e/ou subprodutos de grande valor comercial, juntamente com a mitigação do gás de estufa $\mathrm{CO}_{2}$ por meio do processo fotossintético.

O terceiro artigo com maior número de citações (179), Gonzalez \& Bashan (2000), estuda a coimobilização da microalga Chlorella vulgaris e da bactéria Azospirillum brasilense em pequenos grânulos de alginato, este é um método eficaz de 
aumentar as populações de microalgas em ambientes confinados. O consórcio estudado contribuiu diretamente no aumento dos pigmentos intracelulares da microalga. Os estudos citam principalmente, esse trabalho para fundamentar a relação dos microrganismos na ciclagem dos nutrientes e também na promoção do crescimento algal (De-Bashan et al., 2010; Ramanan et al., 2016). O autor sugere que um controle mais rigoroso da cultura é capaz de promover a eficácia em aplicações industriais e de biorremediação. Gonçalves et al., (2017), artigo com maior média anual de citações (41) consiste em uma revisão sobre o uso de consórcio de microalgas para o tratamento de efluentes com destaque voltado para as interações dos microrganismos constituintes e os mecanismos de remoção de nutrientes.

Os seis artigos restantes da lista serão agora descritos em ordem decrescente da média anual de citações. Samori G. et al., (2013) desenvolveram uma planta piloto de tratamento de águas residuais e produção de biomassa de algas, investigaram o crescimento de uma espécie local isolada e um consórcio de microalgas em efluentes gerados por uma instalação de recuperação de águas residuais local e relataram o desempenho maior da monocultura em termos de produtividade de biomassa, sugerindo a utilização da espécie da pesquisa em sistemas abertos de cultivo. Hena et al., (2015) apresentaram um trabalho abordando o cultivo de microalgas em consórcio em um efluente de origem agroindustrial para a produção de biodiesel e remoção de nutrientes. Chinnasamy et al., (2010) avaliaram a produção em massa do consórcio de algas nativas usando águas residuais não tratadas da indústria de carpetes, sua produtividade em diferentes configurações de cultivo e a estimativa da produção de biometano, revelando a potencialidade de uma abordagem integrada na gestão de resíduos e produção de bioenergia. Renuka et al., (2013) buscaram analisar em termos de remoção de nutrientes a melhoria da qualidade da água e produção de biomassa utilizando esgoto primário tratado e o potencial de consórcios de cepas nativas de microalgas filamentosas, microalgas unicelulares nativas e microalgas selecionadas de germoplasma. Gonzalez-Fernandez et al., (2011) testaram o consórcio de microalgas-bactérias no tratamento de dejetos de suínos (na forma bruta e digerido anaerobicamente) de forma a entender a transformação do nitrogênio. Finalmente, Munoz et al., (2006) estudaram a potencial aplicação do consórcio da microalga Chlorella sorokiniana e da bactéria Ralstonia basilensis, na absorção de Cu (II), íons de metais pesados e poluentes.

\section{Principais Aplicações Relatadas na Literatura}

Para abordar a RQ3: Quais são as principais aplicações relatadas?, realizamos uma análise de conteúdo baseada na interação dos consórcios citados na pesquisa com bioativos (seção 4.1), tratamento de efluentes (seção 4.2) e a combinação de ambos (seção 4.3).

Dentre os 224 artigos da amostra (Figura 6), 116 relacionaram o consórcio de microalgas com o tratamento de efluentes. Destes arquivos, 39 artigos tiveram no seu título ou resumo um ou mais bioativo de interesse. Os demais 77 artigos que abordaram o tratamento de efluentes não correlacionaram com nenhum bioativo que se propôs a instauração do filtro da pesquisa. Os 108 artigos remanescentes da amostra inicial que não abrangem o tratamento tiveram 43 (19\%) trabalhos que abordaram um ou mais bioativos. 
Figura 6 - Principais aplicações dos consórcios MM e MB.

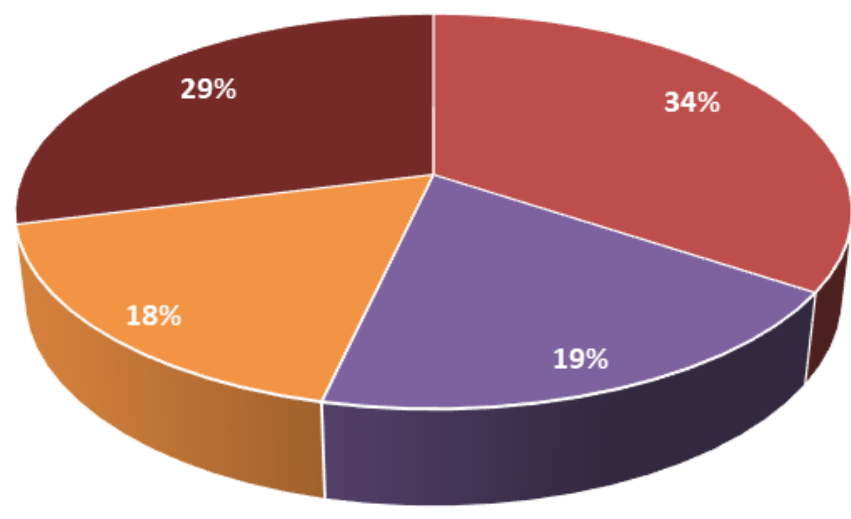

- Tratamento de efluentes " Bioativos | Bioativos+Tratamento de efluentes " Outros

Fonte: Autores (2021).

A Figura 7 relata que a partir do ano de 2015 houve um aumento no número de trabalhos que abordam os consórcios MM e MB como uma alternativa para o tratamento de efluentes sugerindo a utilização desses microrganismos como agentes de biorremediação.

Figura 7 - Distribuição das publicações ao longo dos anos em relação às suas aplicações para ambos os consórcios MM e MB.

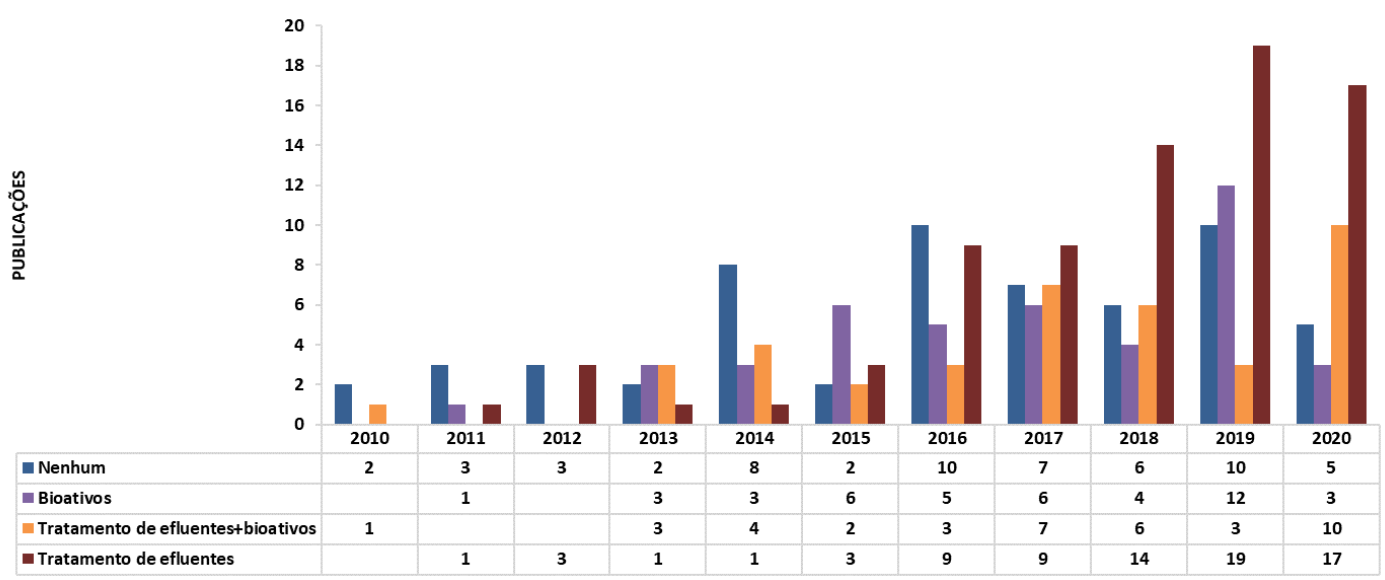

Fonte: Autores (2021).

\subsection{Bioativos}

A partir de alta demanda mundial por novas fontes de energia não poluentes, a produção de biomassa microbiana tem sido investigada. A quantificação de seus compostos é de extrema importância, direcionando assim sua aplicação seja como incremento em rações animais, fonte de hidrocarbonetos para combustíveis e entre outros (Hussain et al., 2021; Katiyar et al., 2017; Morais Junior et al., 2020). Proteínas, carboidratos, lipídios e ácidos graxos são compostos sintetizados por esses microrganismos e amplamente citados na literatura devido ao seu potencial de aplicação (Abu-Ghosh et al., 2021; Sudhakar et al., 2019; Vieira de Mendonça et al., 2021). Diante disto, procurou-se investigar a relação dos dois tipos de consórcio (MM e MB) com esses bioativos (Figura 8). 
Figura 8 - Distribuição de bioativos em consórcio MM e MB.

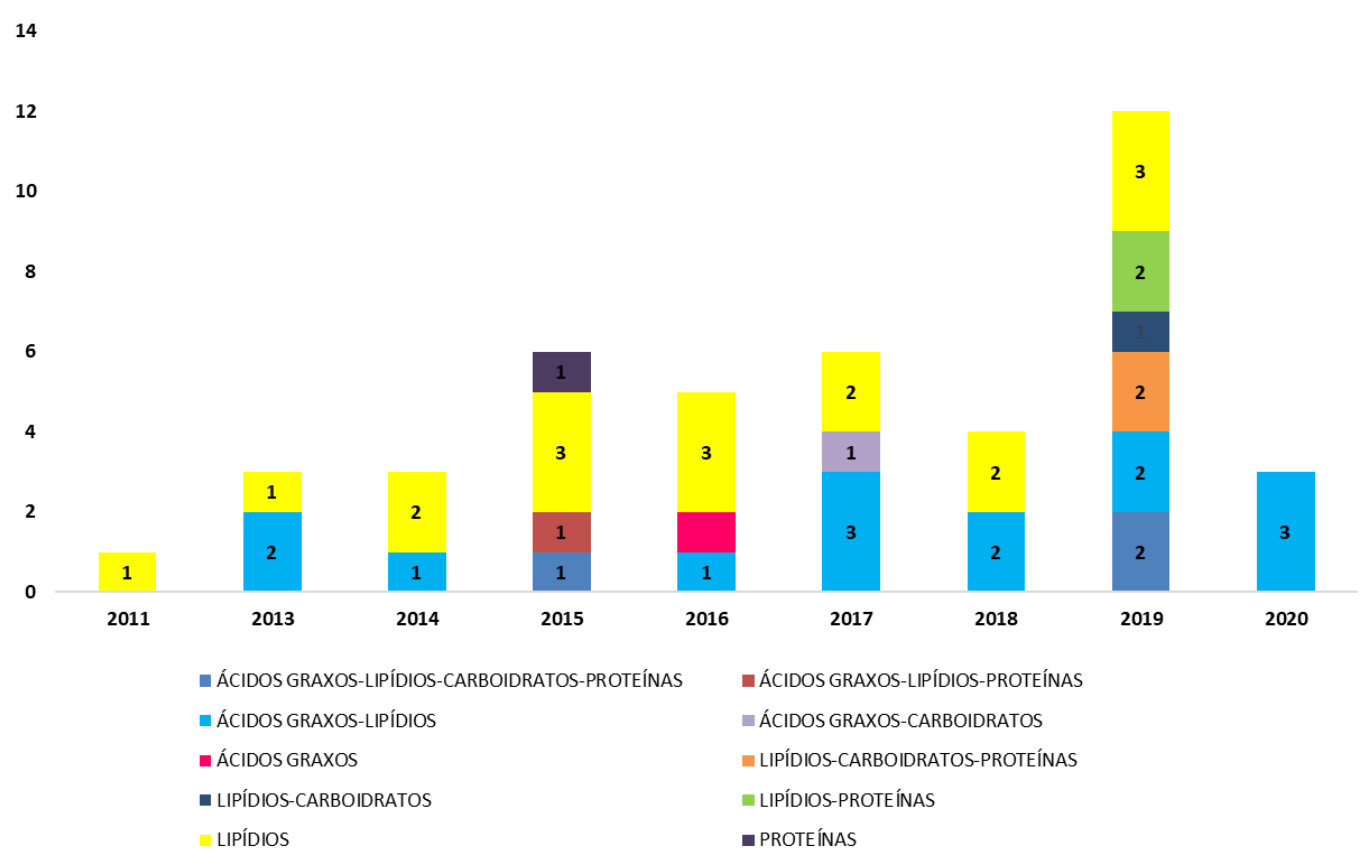

Fonte: Autores (2021).

A Figura 9 traz a distribuição dos trabalhos em que foram identificados um ou mais bioativos de aplicação industrial na biomassa produzida ao longo dos anos para os consórcios do tipo MM. Ao analisarmos a relação de trabalhos que prospectam mais de um metabólito de interesse nos consórcios MM, observamos que os lipídios foram os majoritários e relatados no decorrer dos anos a partir de 2011.

Figura 9 - Bioativos e consórcio de microalgas-microalgas.

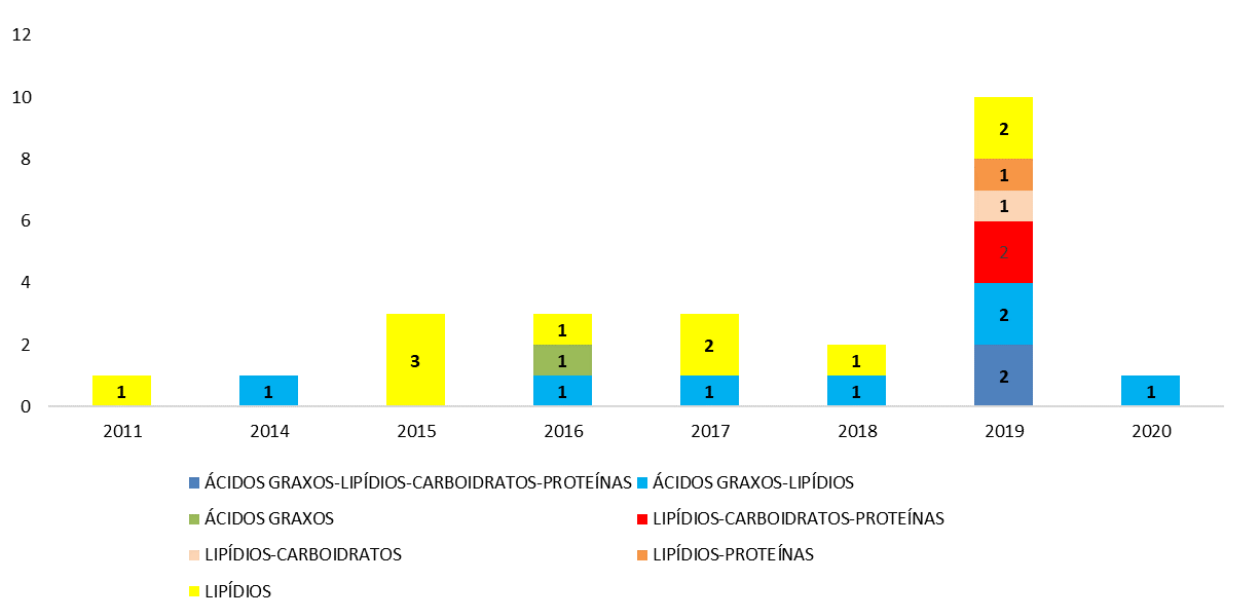

Fonte: Autores (2021).

A quantificação dos metabólitos presentes em consórcios microalgas-bactérias (Figura 10) foi identificada em trabalhos publicados a partir do ano de 2013 e prosseguiu até 2020, possuindo um total de 19 artigos publicados. 
Figura 10 - Bioativos e consórcio de microalgas-bactérias.

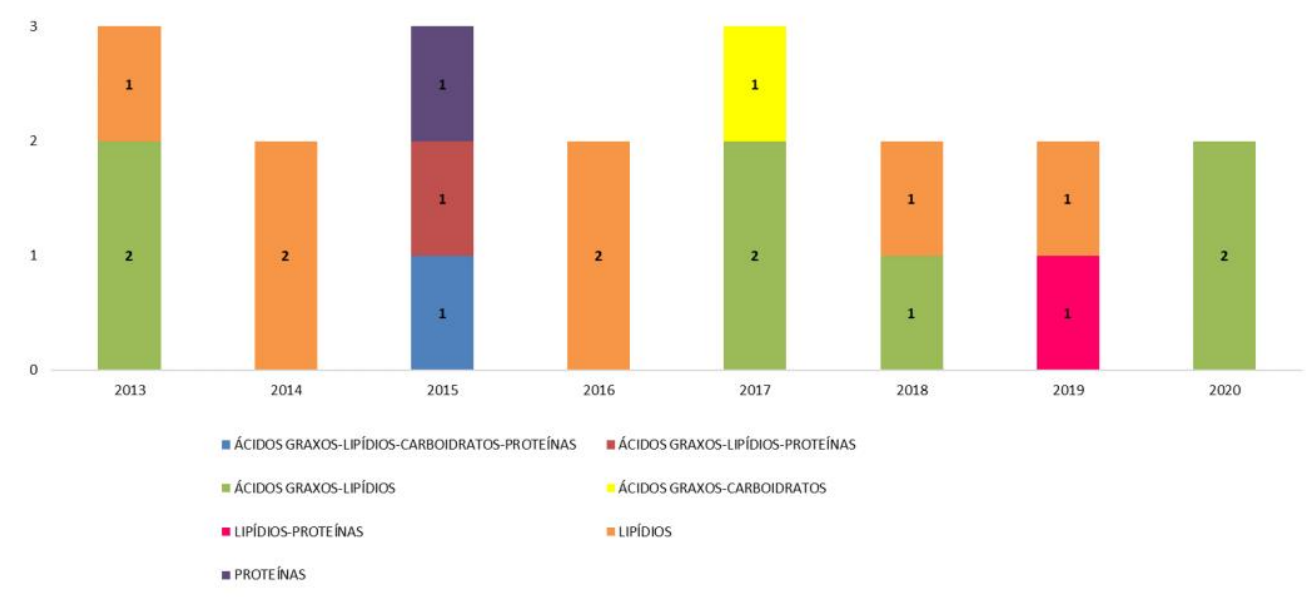

Fonte: Autores (2021).

Como é verificado na Figura 10, os lipídios também foram os principais metabólitos de interesse dentre as publicações de consórcios MB (19 artigos), sendo destes, 7 trabalhos focados apenas no conteúdo lipídico e 11 artigos relacionados com outros metabólitos, com destaque para trabalhos direcionados a composição de ácidos graxos. Independentemente do tipo de consórcio microbiano (MM ou MB) os lipídios foram os metabólitos de maior interesse (Figura 8). A prevalência desses bioativos também se evidenciou na rede de palavras-chave (Figura 3). Podemos entender essa tendência a partir da constante busca por matrizes renováveis ricas em lipídeos, principalmente para produção de biocombustíveis, como exemplo o biodiesel (Mata et al., 2010)

A partir do ano de 2014 houve um aumento nas publicações para ambos os consórcios, tendo seu ápice no ano de 2019. A análise de regressão foi usada para analisar as tendências de crescimento linear o qual foi obtido uma tendência positiva $(\mathrm{R}=0,62)$.

\subsection{Tratamento de efluentes}

Por ser uma alternativa econômica e ambientalmente viável, as microalgas atuam como removedores de componentes presentes no meio, uma vez que estes nutrientes são fundamentais para o crescimento da microalga (Gonçalves et al., 2017). Os trabalhos de revisão destacados na literatura apontam estudos voltados para o consórcio de microalgas-bactérias que atuam de forma sinergética na biorremediação de efluentes e solo ao remover poluentes orgânicos e inorgânicos presentes no meio (Fu \& Secundo, 2016; Mujtaba et al., 2016; Manzoor et al., 2016; Gonçalves et al., 2016; Liu et al., 2017; Perera et al., 2018; Perera et al., 2019). Entre os efluentes estudados nos trabalhos aqui revisados (Quadro 4), os de origem Agroindustrial (efluente proveniente da digestão anaeróbica, resíduo de suínos, efluente de laticínios, efluente rural, etc.) foram os mais utilizados nos consórcios, isso se dá pelas altas concentrações de constituintes químicos, como Nitrogênio, Fósforo e Potássio (Hossain\&Mahlia, 2019), os quais são favoráveis ao desenvolvimento das espécies, seguido pela categoria outros (49) que reúnem efluentes como: metais pesados, pesticidas e componentes químicos. 
Quadro 4 - Procedência de efluentes mais citados na pesquisa.

\begin{tabular}{|c|c|c|}
\hline Origem do efluente & $\mathrm{N}^{\mathbf{o}}$ de documentos & $\begin{array}{c}\mathrm{N}^{\mathbf{0}} \text { de documentos por tipo de } \\
\text { consórcio }\end{array}$ \\
\hline Agroindustrial & 34 & $\begin{array}{c}\mathrm{MM}=13 \\
\mathrm{MB}=21\end{array}$ \\
\hline Industrial & 10 & $\begin{array}{c}\mathrm{MM}=3 \\
\mathrm{MB}=7\end{array}$ \\
\hline Municipal & 23 & $\mathrm{MM}=6$ \\
& & $\mathrm{MB}=17$ \\
\hline Outros & 49 & $\begin{array}{c}\mathrm{MM}=10 \\
\mathrm{MB}=39\end{array}$ \\
\hline
\end{tabular}

Fonte: Autores (2021).

\subsection{Bioativos e tratamento de efluentes}

Do mesmo modo, o beneficiamento da biomassa microalgal gerada ao fim do processo, avaliando os bioativos de interesse que fazem parte de sua composição centesimal, é um campo recente de pesquisa (2010 - atualidade). Os estudos relacionados à produção de lipídios em consórcios MM e MB são os mais abordados pela literatura (30 publicações) como aponta a Figura 11.

Figura 11 - Distribuição de bioativos nos consórcios MM e MB no tratamento de efluentes.

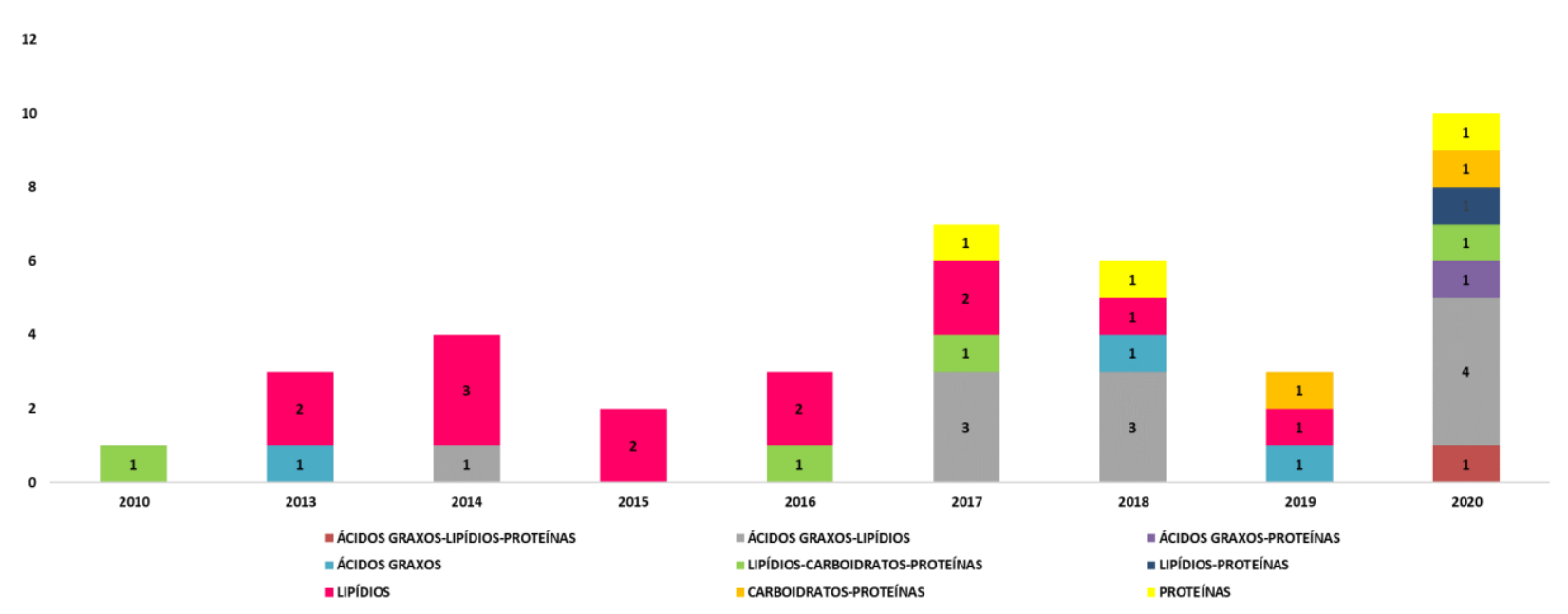

Fonte: Autores (2021).

O primeiro trabalho que relata a quantificação dos metabólitos produzidos em consórcios MM, Chinnasamy S, et al., (2010), buscou avaliar a produtividade do consórcio de microalgas (Chlamydomonas globosa, Chlorella minutissima e Scenedesmus bijuga) na produção de bioenergia usando águas residuais da indústria de carpetes. Entre os diferentes sistemas de cultivo estudados o mais produtivo foi o reator de polybag, gerando uma biomassa rica em compostos bioativos, com cerca de: 5,3\% de lipídeos, $15,7 \%$ de carboidratos e 53,8\% de proteínas.

Hernández et al., (2013) buscou avaliar a atuação de um sistema integrado por um consórcio de microalgas-bactérias para o tratamento de águas residuais (indústria de processamento de batatas e esterco de suínos) combinado com a digestão anaeróbica da biomassa produzida. O estudo verificou uma produtividade máxima de $26,30 \mathrm{mg}$ de peso seco $\mathrm{L}^{-1} \mathrm{~d}^{-1}$ quando cultivado em esterco de suíno e a concentração de lipídios atingiu 30,20\% no resíduo de processamento da indústria de batatas e 4,30\% no esterco de suíno. 


\section{Lacunas na Literatura e Oportunidades para Pesquisas Futuras}

Diante da necessidade de mitigação dos impactos causados pelas atividades agrícolas, industriais e a urbanização, a busca por alternativas tecnológicas que atuem em conjunto na geração de produtos é um tópico que traz desafios para a produção em escala ampliada. $\mathrm{O}$ aumento no número de trabalhos voltados para a temática de consórcios de microalgas consiste principalmente no interesse da utilização destes como agentes de remediação de efluentes.

Os consórcios podem atuar de forma integrada na manutenção dos recursos hídricos e na geração de uma biomassa aplicável. Os principais desafios destacados pelos autores consistem na necessidade de estudos de consórcios, principalmente de organismos fotossintéticos, ambientados em grande escala a fim de averiguar a influência das condições ambientais no seu desenvolvimento e otimizar os parâmetros de cultivo. Trabalhos que demonstrem a potencialidade de utilização da biomassa do consórcio para outras aplicações, como por exemplo, o de uso como fonte nutricional para alimentação animal ainda são poucos relatados na literatura, bem como estudos de viabilidade econômica e de implementação desses sistemas de cultivo em áreas rurais.

\section{Conclusões}

O presente trabalho buscou apresentar uma visão panorâmica do que a literatura tem discutido sobre consórcios de microalgas e foi possível observar um crescimento expressivo nas publicações que trabalharam este tema de 1996 a 2020. Para tanto, foi realizado uma Revisão Sistemática da Literatura (RSL) em que se utilizou de ferramentas de estatística para a quantificação e avaliação da produção científica no que tange número de publicações, principais autores, periódicos e temas recorrentes que estão associados ao consórcio.

Esta revisão relatou a potencialidade de utilização de consórcios microbianos para o desenvolvimento de novas tecnologias que visem a mitigação de impactos ambientais e sejam coordenadas por conceitos de bioeconomia circular. Ficou evidente que a busca e realização de trabalhos que envolvem consórcios ganhou maior destaque a partir da última década. A mesma lógica também é aplicada quando se investiga os compostos bioativos presentes na biomassa do consórcio e no tratamento de efluentes em que se utilizam co-cultivos como agentes de biorremediação. A predominância se encontra na possibilidade de uso da biomassa para biocombustíveis em sua maioria biodiesel.

Por utilizar apenas uma base de dados e se limitar apenas a um idioma, a amostra poderia abranger uma diversidade maior de autores e estudos que compreendem uma variedade de aplicações para estes consórcios. Além disso, as lacunas tecnológicas como aplicações para a biomassa, estudos de viabilidade e implementação dos sistemas de cultivo apresentados neste trabalho são um desafio para os avanços na pesquisa em relação ao tema. Sugere-se que sejam feitas pesquisas de cunho exploratório para descoberta de espécies que apresentem maior tolerância à meios com elevados níveis de toxicidade a fim de obter uma biomassa de baixo custo e aplicabilidade comercial, bem como trabalhos voltados para a expansão, implementação de sistemas de cultivo e processamento da biomassa obtida.

\section{Referências}

Abu-Ghosh, S., Dubinsky, Z., Verdelho, V., \& Iluz, D. (2021). Unconventional high-value products from microalgae: A review. Bioresource Technology, 329, 124895. https://doi.org/10.1016/J.BIORTECH.2021.124895

Bornmann, L. and Leydesdorff, L. (2013). The validation of (advanced) bibliometric indicators through peer assessments: A comparative study using data from InCites and F1000. Journal of informetrics, 7(2), pp.286-291.

Chew, K. W., Chia, S. R., Show, P. L., Yap, Y. J., Ling, T. C., \& Chang, J. S. (2018). Effects of water culture medium, cultivation systems and growth modes for microalgae cultivation: A review. Journal of the Taiwan Institute of Chemical Engineers, 91, 332-344. https://doi.org/10.1016/J.JTICE.2018.05.039 
Chapin Iii, F.S., Zavaleta, E.S., Eviner, V.T., Naylor, R.L., Vitousek, P.M., Reynolds, H.L., Hooper, D.U., Lavorel, S., Sala, O.E., Hobbie, S.E. and Mack, M.C. (2000). Consequences of changing biodiversity. Nature, 405(6783), pp.234-242.

Chinnasamy S, Bhatnagar A, Claxton R, Das KC. Biomass and bioenergy production potential of microalgae consortium in open and closed bioreactors using De-Bashan, L.E. \& Bashan, Y., (2010). Immobilized microalgae for removing pollutants: review of practical aspects. Bioresource technology, 101(6), pp.1611-1627.

Dayana Priyadharshini, S., Suresh Babu, P., Manikandan, S., Subbaiya, R., Govarthanan, M., \& Karmegam, N. (2021). Phycoremediation of wastewater for pollutant removal: A green approach to environmental protection and long-term remediation. Environmental Pollution, $290,117989$. https://doi.org/10.1016/J.ENVPOL.2021.117989

Denyer, D., Tranfield D. Producing a Systematic Review. In: The Sage 49 Handbook of Organizational Research Methods. Thousand Oaks: Sage Publications Ltd., 2009. p. 671-689.

Fakhimi, N., Gonzalez-Ballester, D., Fernández, E., Galván, A., \& Dubini, A. (2020). Algae-Bacteria Consortia as a Strategy to Enhance H2 Production. Cells, 9(6), 1353. MDPI AG. Retrieved from http://dx.doi.org/10.3390/cells9061353

Fallahi, A., Rezvani, F., Asgharnejad, H., Khorshidi, E., Hajinajaf, N., \& Higgins, B. (2021). Interactions of microalgae-bacteria consortia for nutrient removal from wastewater: A review. Chemosphere, 272, 129878. https://doi.org/10.1016/J.CHEMOSPHERE.2021.129878

Fu P., Secundo F. (2016) Algae and their bacterial consortia for soil bioremediation, Chemical Engineering Transactions, 49, 427-432 DOI: $10.3303 /$ CET1649072

Fu, Y., Chen, T., Chen, S. H. Y., Liu, B., Sun, P., Sun, H., \& Chen, F. (2021). The potentials and challenges of using microalgae as an ingredient to produce meat analogues. Trends in Food Science \& Technology, 112, 188-200. https://doi.org/10.1016/J.TIFS.2021.03.050

Gonçalves, A. L., Pires, J. C. M., \& Simões, M. (2016). Biotechnological potential of Synechocystis salina co-cultures with selected microalgae and cyanobacteria: Nutrients removal, biomass and lipid production. Bioresource Technology, 200, 279-286. https://doi.org/10.1016/J.BIORTECH.2015.10.023

Gonçalves, A. L., Pires, J. C. M., \& Simões, M. (2017). A review on the use of microalgal consortia for wastewater treatment. Algal Research, $24,403-415$. https://doi.org/10.1016/J.ALGAL.2016.11.008

González-Gálvez, O. D., Nava Bravo, I., Cuevas-García, R., Velásquez-Orta, S. B., Harvey, A. P., Cedeño Caero, L., \& Orta Ledesma, M. T. (2020). Bio-oil production by catalytic solvent liquefaction from a wild microalgae consortium. Biomass Conversion and Biorefinery. https://doi.org/10.1007/s13399-02000716-y

Hernández, D., Riaño, B., Coca, M., \& García-González, M. C. (2013). Treatment of agro-industrial wastewater using microalgae-bacteria consortium combined with anaerobic digestion of the produced biomass. Bioresource Technology, 135, 598-603. https://doi.org/10.1016/J.BIORTECH.2012.09.029

Hossain, N., \& Mahlia, T. (2019) Progress in physicochemical parameters of microalgae Cultivation for biofuel production. Critical Reviews in Biotechnology, 39(6), 835-859.

Hu, J., Nagarajan, D., Zhang, Q., Chang, J. S., \& Lee, D. J. (2018). Heterotrophic cultivation of microalgae for pigment production: A review. Biotechnology Advances, 36(1), 54-67. https://doi.org/10.1016/J.BIOTECHADV.2017.09.009

Hussain, F., Shah, S. Z., Ahmad, H., Abubshait, S. A., Abubshait, H. A., Laref, A., Manikandan, A., Kusuma, H. S., \& Iqbal, M. (2021). Microalgae an ecofriendly and sustainable wastewater treatment option: Biomass application in biofuel and bio-fertilizer production. A review. Renewable and Sustainable Energy Reviews, 137, 110603. https://doi.org/10.1016/J.RSER.2020.110603

Ishika, T., Moheimani, N. R., \& Bahri, P. A. (2017). Sustainable saline microalgae co-cultivation for biofuel production: A critical review. Renewable and Sustainable Energy Reviews, 78, 356-368. https://doi.org/10.1016/J.RSER.2017.04.110

Juneja, A.; Ceballos, R. M. \& Murthy, G.S. (2013) Effects of environmental factors and nutrient availability on the biochemical composition of algae for biofuels production: a review. Energies, 6(9), 4607-4638.

Katiyar, R., Gurjar, B. R., Biswas, S., Pruthi, V., Kumar, N., \& Kumar, P. (2017). Microalgae: An emerging source of energy based bio-products and a solution for environmental issues. Renewable and Sustainable Energy Reviews, 72, 1083-1093. https://doi.org/10.1016/J.RSER.2016.10.028

Kitchenham, B. (2004). Procedures for performing systematic reviews. Keele, UK, Keele University, 33(TR/SE-0401), 28. http://doi.org/10.1.1.122.3308

Liu, J., Wu, Y., Wu, C., Muylaert, K., Vyverman, W., Yu, H. Q., Muñoz, R., \& Rittmann, B. (2017). Advanced nutrient removal from surface water by a consortium of attached microalgae and bacteria: A review. Bioresource Technology, 241, 1127-1137. https://doi.org/10.1016/J.BIORTECH.2017.06.0541093. 2017.

Magdouli, S., Brar, S. K., \& Blais, J. F. (2016). Co-culture for lipid production: Advances and challenges. Biomass and Bioenergy, 92, 20-30. https://doi.org/10.1016/J.BIOMBIOE.2016.06.003

Manzoor, Maleeha \& Ma, Ruijuan \& Shakir, Hafiz \& Tabssum, Fouzia \& Qazi, Javed. (2016). Microalgal-bacterial consortium: A cost-effective approach of wastewater treatment in Pakistan. Punjab university journal of zoology. 31. 307-320.

Mata, T. M., Martins, A. A., \& Caetano, N. S. (2010b). Microalgae for biodiesel production and other applications: A review. Renewable and Sustainable Energy Reviews, 14(1), 217-232. https://doi.org/10.1016/J.RSER.2009.07.020

Morais Junior, W. G., Gorgich, M., Corrêa, P. S., Martins, A. A., Mata, T. M., \& Caetano, N. S. (2020). Microalgae for biotechnological applications: Cultivation, harvesting and biomass processing. Aquaculture, 528, 735562. https://doi.org/10.1016/J.AQUACULTURE.2020.735562 
Moreno-Garcia, L., Adjallé, K., Barnabé, S., \& Raghavan, G. S. V. (2017). Microalgae biomass production for a biorefinery system: Recent advances and the way towards sustainability. Renewable and Sustainable Energy Reviews, 76, 493-506. https://doi.org/10.1016/J.RSER.2017.03.024

Mujtaba, Ghulam, \& Lee, Kisay. (2016). Advanced Treatment of Wastewater Using Symbiotic Co-culture of Microalgae and Bacteria. Applied Chemistry for Engineering, 27(1), 1-9. https://doi.org/10.14478/ACE.2016.1002

Nath, A., Tiwari, P. K., Rai, A. K., \& Sundaram, S. (2019). Evaluation of carbon capture in competent microalgal consortium for enhanced biomass, lipid, and carbohydrate production. 3 Biotech, 9(11), 1-15. https://doi.org/10.1007/s13205-019-1910-6

Padmaperuma, G; Kapoore, R.V.; = Gilmour, D. J.; Vaidyanathan, S. (2018) Microbial consortia: a critical look at microalgae co-cultures for enhanced biomanufacturing, Critical Reviews in Biotechnology, 38:5, 690-703, DOI: 10.1080/07388551.2017.1390728

Perera, Isiri \& Subashchandrabose, Suresh \& Kadiyala, Venkateswarlu \& Naidu, Ravi \& Mallavarapu, Megharaj. (2018). Consortia of cyanobacteria/microalgae and bacteria in desert soils: an underexplored microbiota. Applied Microbiology and Biotechnology. 102. 10.1007/s00253-018-91921.

Perera, I. A., Abinandan, S., Subashchandrabose, S. R., Venkateswarlu, K., Naidu, R., \& Megharaj, M. (2019). Advances in the technologies for studying consortia of bacteria and cyanobacteria/microalgae in wastewaters. Critical Reviews in Biotechnology, 39(5), 709-731. https://doi.org/10.1080/07388551.2019.1597828

Pires, J. C.M.; Alvim-Ferraz, M. C.M; Martins, F.G. (2017). Photobioreactor design for microalgae production through computational fluid dynamics: A review. Renewable and Sustainable Energy Reviews, 79, 248-254.

Ramanan, R., Kim, B.H., Cho, D.H., Oh, H.M. and Kim, H.S., 2016. Algae-bacteria interactions: evolution, ecology and emerging applications. Biotechnology advances, 34(1), 14-29.

Rashid,N., Ryu, A.E., Jeong, K.J., Lee, B. , Chang, Y. Co-cultivation of two freshwater microalgae species to improve biomass productivity and biodiesel production, Energy Conversion and Management, 196, 640-648, 2019. https://doi.org/10.1016/j.enconman.2019.05.106.

Rossi S., Sforza E., Pastore M. , Bellucci M. , Casagli F. , F Marazzi. \& Ficara E. .Photo-respirometry to shed light on microalgae-bacteria consortia-a review. Rev Environ Sci Biotechnol 19, 43-72 (2020). https://doi.org/10.1007/s11157-020-09524-2

Smith, T.P., Thomas, T.J., García-Carreras, B., Sal, S., Yvon-Durocher, G., Bell, T. \& Pawar, S., (2019). Community-level respiration of prokaryotic microbes may rise with global warming. Nature communications, 10(1), 1-11.

Sorz, J., Glänzel, W., Ulrych, U., Gumpenberger C. \& Gorraiz J. (2020). Research strengths identified by esteem and bibliometric indicators: a case study at the University of Vienna. Scientometrics $125,1095-1116$.

Sudhakar, M. P., Kumar, B. R., Mathimani, T., \& Arunkumar, K. (2019). A review on bioenergy and bioactive compounds from microalgae and macroalgaesustainable energy perspective. Journal of Cleaner Production, 228, 1320-1333. https://doi.org/10.1016/J.JCLEPRO.2019.04.287

Vieira de Mendonça, H., Assemany, P., Abreu, M., Couto, E., Maciel, A. M., Duarte, R. L., Barbosa dos Santos, M. G., \& Reis, A. (2021). Microalgae in a global world: New solutions for old problems? Renewable Energy, 165, 842-862. https://doi.org/10.1016/J.RENENE.2020.11.014

Wu, J. Y., Lay, C. H., Chiong, M. C., Chew, K. W., Chen, C. C., Wu, S. Y., Zhou, D., Kumar, G., \& Show, P. L. (2020). Immobilized Chlorella species mixotrophic cultivation at various textile wastewater concentrations. Journal of Water Process Engineering, 38, 101609. https://doi.org/10.1016/J.JWPE.2020.101609

Zhang, B., Li, W., Guo, Y., Zhang, Z., Shi, W., Cui, F., Lens, P. N. L., \& Tay, J. H. (2020). Microalgal-bacterial consortia: From interspecies interactions to biotechnological applications. Renewable and Sustainable Energy Reviews, 118,109563. https://doi.org/10.1016/j.rser.2019.109563 